\title{
Evolving Pandemic Diabetic Nephropathy
}

\author{
Eli A. Friedman, M.D.* \\ Distinguished Teaching Professor of Medicine, Downstate Medical Center, Brooklyn, New York, USA
}

\begin{abstract}
The expanding impact of chronic kidney disease (CKD) due to pandemic diabetes mellitus is recounted emphasizing its epidemiology that has induced global socioeconomic stress on health care systems in industrialized nations now attempting to proffer optimal therapy for end stage renal disease (ESRD). Strategies to delay and perhaps prevent progression of diabetic nephropathy from minimal proteinuria through nephrotic range proteinuria and azotemia to ESRD appear to have decreased the rate of persons with diabetes who develop ESRD. For those with ESRD attributed to diabetes, kidney transplantation affords better survival and rehabilitation than either hemodialysis or peritoneal dialysis. It is likely that advances in genetics and molecular biology will suggest early interventions that will preempt diabetic complications including renal failure.
\end{abstract}

KEY WORDS: diabetic nephropathy, chronic kidney disease, glycation, renal failure, renoprotection

Kidney failure in persons with diabetes has grown to be the dominant concern of the unique federal program established as a component of Medicare, that since 1972 funds maintenance hemodialysis, peritoneal dialysis, and renal transplantation for end stage renal disease (ESRD). Diabetes mellitus, initially a reason for exclusion from ESRD treatment in the 1970s, has continuously expanded to lead the list of treatable causes of irreversible renal failure to the extent that $44.6 \%$ of incident treated patients in 2006 had recognized diabetes as recorded by the United States Renal Data System (USRDS) through $2008 .{ }^{1}$ An additional $6.5 \%$ of patients commencing ESRD therapy had diabetes that was not noted on their Medicare Report Form. A further $10 \%$ of incident ESRD patients had diabetes diagnosed during their first year of ESRD treatment meaning that a minimum of six out of ten new ESRD patients had diabetes. ESRD and diabetes were intertwined as major drains on health resources.

The World Health Organization (WHO) predicts ongoing sharp global expansion of diabetes incidence and prevalence, estimating that by 2025 more than 300 million persons will have diabetes, raising the specter of a "Pandemic" threatening imminent collapse of socioeconomic

\begin{abstract}
Abbreviations: ACEi, angiotensin-converting enzyme inhibitor; ACR, albumin-to-creatinine ratio; AGE, advanced glycosylated endproducts; ANA, antinuclear autoantibodies; ARB, angiotensin receptor blocker; CKD, chronic kidney disease; ESRD, end stage renal disease; GFR, glomerular filtration rate; PKC, protein kinase C; RAGE, the receptor for advanced glycation endproducts; USRDS, United States Renal Data System; WHO, World Health Organization.
\end{abstract}

Citation: Friedman EA. Evolving Pandemic Diabetic Nephropathy. RMMJ 2010;1(1):eooo5. doi:10.5041/RMMJ.10005

Copyright: (C) 2010 Eli A. Friedman. This is an open-access article. All its content, except where otherwise noted, is distributed under the terms of the Creative Commons Attribution License (http://creativecommons.org/licenses/by/3.o), which permits unrestricted use, distribution, and reproduction in any medium, provided the original work is properly cited.

Conflict of interest: No potential conflict of interest relevant to this article was reported.

* E-mail: Elifriedmn@aol.com 
and fiscal resources available to confront the disease onslaught. By most recent WHO estimates, while in 2000170 million people world-wide had diabetes, by 2030 the number afflicted will reach 370 million. India and China top the "endangered" list of countries with more than 120 million persons predicted to manifest diabetes in those two countries alone. In 2005, an estimated 1.1 million people died from diabetes. WHO projects that diabetes deaths will increase by more than $50 \%$ in the next 10 years without urgent action. Most notably, diabetes deaths will increase by over $80 \%$ in upper-middle income countries between 2009 and 2019. ${ }^{2}$

Other than expression of alarm, there have been minimal structured efforts to prepare for a diabetes pandemic. In 2003, the author observed that: "Europe is locked in the grip of a pandemic of diabetes that now engulfs the new world. ${ }^{3} \mathrm{Di}-$ abetes mellitus leads the causes of ESRD in the United States, Japan, and most nations in industrialized Europe." National ESRD registries report that both glomerulonephritis and hypertensive renal disease rank below diabetes in frequency of diagnosis among new ESRD patients, substantiating the prescient contention by Mauer and Chavers, in 1985, that "Diabetes is the most important cause of ESRD in the Western world". ${ }^{4}$ Lacking any proactive plan to confront a diabetes induced ESRD pandemic, the United States and other developed nations have assumed a posture of "watchful waiting".

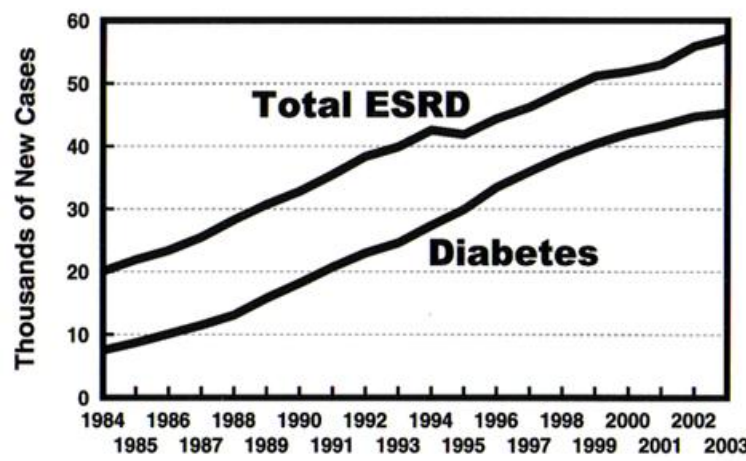

Figure 1. End stage renal failure incidence in the USA, compiled by the United States Renal Data System (USRDS), 2005. There has been a continuing increase in the number of new cases of ESRD between 1984 and 2003. The major diagnosis driving the upward curve is in persons with diabetes.

Recently, however, study of the incidence curves for ESRD associated with diabetes based on data collected by the USRDS affords reason to believe that the epidemic tide is turning. Projections of unrelenting growth of diabetes and its prime complication of ESRD based on annual incident patient counts compiled by the USRDS from 1984 through 2003 were starkly frightening as shown in Figure 1. Incidence counts for the last ten years, however, show a blunting of the upward curve of incident patient counts, evident from incidence counts for 1998 through 2003 (Figure 2).

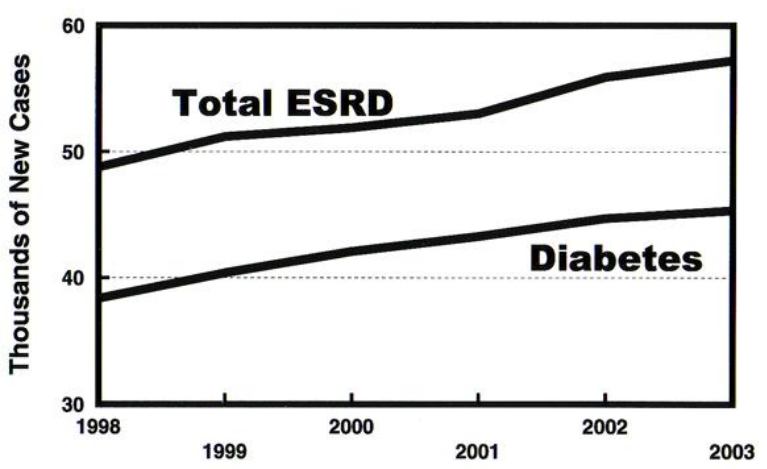

Figure 2. End stage renal failure incidence in the USA, compiled by the United States Renal Data System (USRDS), 2005. From 1998 to 2003, there has been a flattening of the epidemic growth curves for both diabetes and all ESRD cases. The major kidney disorder driving the upward curve is diabetes.

ESRD increasingly has been transformed into a geriatric disorder. As depicted in the annual data reports of the USRDS, the mean age of newly treated (incident) ESRD patients in the US has increased to above age 60 while those with diabetes are approximately two years older than those without diagnosed diabetes (Figure 4).

\section{NATURAL HISTORY OF DIABETIC NEPHROPATHY}

Kidney disease in diabetes begins with the pathophysiologic perturbations of increased glomerular filtration rate (GFR) termed hyperfiltration, and the excretion of small amounts of albumin termed microalbuminuria (Figure 5). Thereafter, proteinuria, nephrosis, azotemia, and ESRD follow in sequence. Careful observation of the course of nephropathy in type 1 and type 2 diabetes indicates strong similarities in rate of renal functional deterioration 5 and onset of comorbid complications. Early nephromegaly, as 


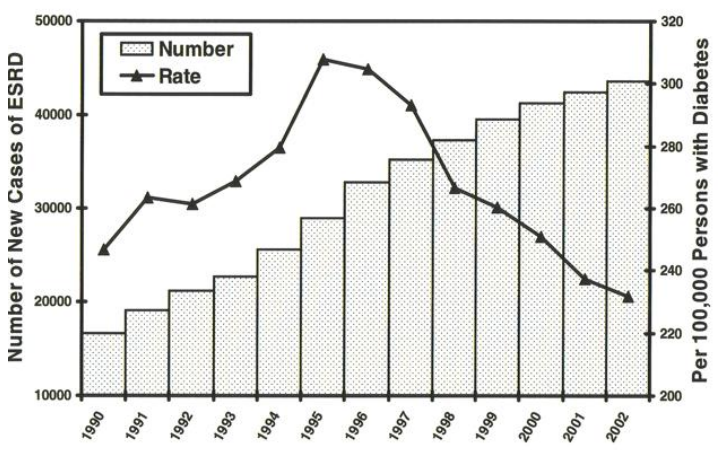

Figure 3. New onset end stage renal disease (ESRD) in persons with diabetes expressed as both incident number and incident rate of new onset ESRD per 100,000 persons with diabetes (United States Renal Data System (USRDS) data, 2006 (age adjusted)). A sharp decline in the incident rate starting in 1995 is evident. This observation was noted in the Centers for Disease Control and Prevention (CDC)'s Weekly Morbidity and Mortality Report in November, 2005. Inferred from this finding is the ongoing subsidence of the pandemic of ESRD in persons with diabetes .

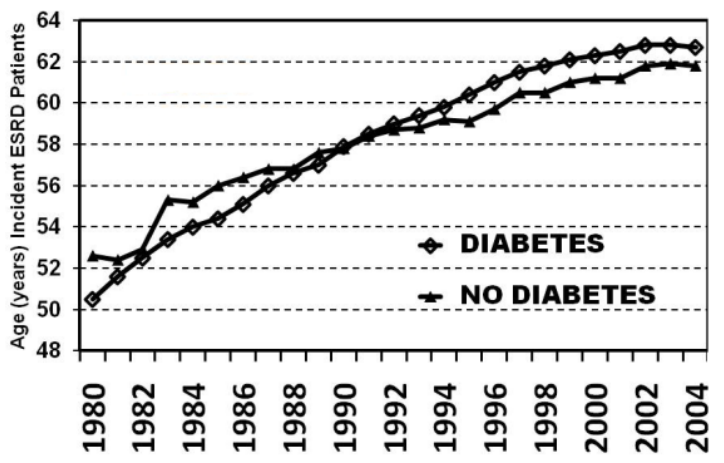

Figure 4. Age incident of newly treated diabetic and non-diabetic end stage renal disease (ESRD) patients in the USA between 1980 and 2004 (United States Renal Data System (USRDS) data, 2007).

well as both glomerular hyperfiltration and microalbuminuria, previously thought limited to type 1 diabetes, are now recognized as equally prevalent in type 2 diabetes. ${ }^{6}$ Lack of precision in diabetes classification provokes confusing terms such as "insulin requiring" to explain treatment with insulin in persons thought to have resistant type 2 diabetes. In fact, present criteria are unable to classify as many as one-half of diabetic persons as specifically type 1 or type 2 diabetes. ${ }^{7,8}$ Consequently, literature reports of the

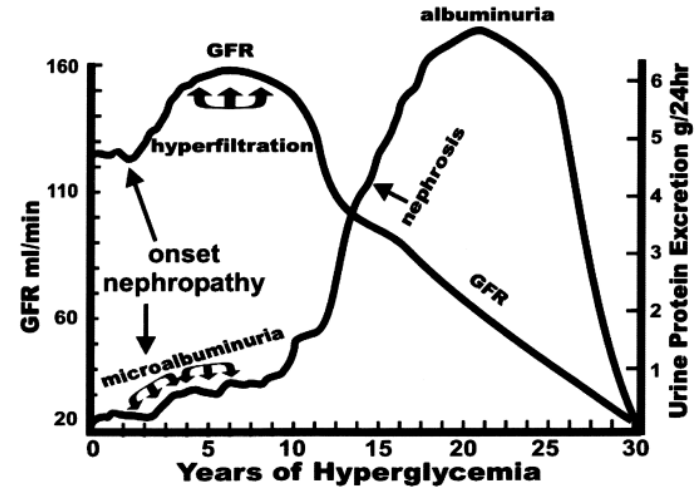

Figure 5. Usually first signaled by detection of small amounts ( $>30 \mathrm{mg} /$ day) of albuminuria, the course of renal injury in individuals with diabetes is remarkably consistent and is characterized by initial nephromegaly and glomerular hyperfiltration followed by an inexorable loss of GFR accompanied by increasing proteinuria and subsequent azotemia.

outcome of ESRD therapy by diabetes type are few and imprecise.

\section{DIABETIC COMPLICATIONS: AD- VANCED GLYCOSYLATED ENDPRO- DUCTS (AGEs)}

In health, protein alteration resulting from a non-enzymatic reaction between ambient glucose and primary amino groups on proteins to form glycated residues called Amadori products is termed the Maillard reaction. After a series of dehydration and fragmentation reactions, Amadori products are transformed to stable covalent adducts called advanced glycosylation endproducts (AGEs). In diabetes, accelerated synthesis and tissue deposition of AGEs is proposed as a contributing mechanism in the pathogenesis of clinical complications. ${ }^{9}$ Accumulation of AGEs in the human body progresses in aging and in complications of renal failure ${ }^{10}$ and diabetes. ${ }^{11}$ AGEs are bound to a cell surface receptor (RAGE) inducing expression of vascular cell adhesion molecule-1 (VCAM-1), an endothelial cell surface cell-cell recognition protein that can prime diabetic vasculature for enhanced interaction with circulating monocytes thereby initiating vascular injury. In addition to angiotensin-converting enzyme, chymase has been indicted as an important alternative angiotensin II-generating enzyme in hypertension and diabetes but the mechanism of chymase induction is unknown. Immunohistochemistry study of coronary and renal 
arteries obtained at autopsy found chymase is up-regulated in patients with diabetes along with deposition of AGEs and RAGE. It is theorized that AGEs, a hallmark of complications in diabetes, induce chymase which provokes oxidative stress via the RAGE-ERK1/2 MAP kinase pathway. ${ }^{12}$

The Oxidative Stress Hypothesis proposes that: hyperglycemia stimulates synthesis of oxygen free radicals that act as mediators of diabetesassociated complications. Oxidative stress is strongly implicated as a mediator of multiple diabetes-induced microvascular complications, including nephropathy, retinopathy, and distal symmetric polyneuropathy. Key mediators of glucose-induced oxidative injury are superoxide anions and nitric oxide (NO). One proposed sequence of how hyperglycemia leads to oxidative stress is that high ambient glucose levels increase mitochondrial synthesis of reactive oxygen species, activates protein kinase $\mathrm{C}$ (PKC) and overexpresses sorbitol. Superoxides are believed to underlie many of the oxidative changes in hyperglycemic conditions, including increases in aldose reductase and protein kinase $\mathrm{C}$ activity.

Mitochondrial superoxide may facilitate complications through increased synthesis of NO and, consequently, formation of the strong oxidant peroxynitrite and by poly(adenosine diphosphate-ribose) polymerase activation. ${ }^{13} \mathrm{Re}-$ sulting endothelial dysfunction and activation of inflammation in blood vessels drives progression of micro- and macrovasculopathy. ${ }^{14}$

Glomerular hyperfiltration, characteristic of the clinically silent early phase of diabetic nephropathy may be induced by Amadori protein products - in rats, infusion of glycated serum proteins induces glomerular hyperfiltration. ${ }^{15}$ NO, produced by endothelial cells, the most powerful vasodilator influencing glomerular hemodynamics, has enhanced activity in early experimental diabetes. ${ }^{16}$ Subsequently, AGEs, by quenching nitric oxide synthase activity, limit vasodilation and reduce glomerular filtration rate. ${ }^{17}$ Clarification of the interaction of AGEs with NO may unravel the mystery of the biphasic course of diabetic glomerulopathy - sequential hyperfiltration followed by diminished glomerular filtration.

Pharmacologic prevention of AGE formation is an attractive means of preempting diabetic microvascular complications because it bypasses the necessity of having to attain euglycemia, an often unattainable goal. Pimagidine (aminoguanidine), interferes with non-enzymatic glyco- sylation ${ }^{18}$ and reduces measured AGE levels leading to its investigation as a potential treatment. Pimagidine was selected because its structure is similar to a-hydrazinohistidine, a compound known to reduce diabetes-induced vascular leakage, while having opposite effects on histamine levels. ${ }^{19}$

Pimagidine treatment in rats made diabetic with streptozotocin preempts complications viewed as surrogates for human diabetic complications: 1) Preventing development of cataracts in rats 90 days after being made "moderately diabetic" ( $<350 \mathrm{mg} / \mathrm{dL}$ plasma glucose); lens soluble and insoluble AGE fractions were inhibited by $56 \%$ and $75 \%$ by treatment with aminoguanidine $25 \mathrm{mg} / \mathrm{kg}$ body weight starting from the day of streptozotocin injection. ${ }^{20}$ 2) Blocking AGE accumulation (measured by tissue fluorescence) in glomeruli and renal tubules in rats 32 weeks after induction of diabetes 32 weeks earlier; ponalrestat, an aldose reductase inhibitor, did not block AGE accumulation. ${ }^{21}$ Preventing glomerular basement membrane thickening typical of renal morphologic changes noted in this model of diabetic nephropathy. Blocking AGE formation to impede development of diabetic complications is an attractive strategy because of elimination of the necessity for euglycemia. ${ }^{22}$

Uremia in diabetes is associated with both a high serum level of AGEs and accelerated macroand microvasculopathy. The renal clearance of AGE-peptides is $0.720 .23 \mathrm{~mL} / \mathrm{min}$ for normal subjects and $0.610 .2 \mathrm{~mL}$ for diabetics with normal glomerular filtration ( $P$-value NS). ${ }^{23}$ Diabetic uremic patients accumulate advanced glycosylated endproducts in "toxic" amounts that are not decreased to normal by hemodialysis or peritoneal dialysis 24 but fall sharply, to within the normal range, within 8 hours of restoration of half-normal glomerular filtration by renal transplantation. ${ }^{25}$ A disarming, counterintuitive and unexplained report of survival in diabetic patients undergoing maintenance hemodialysis noted that there was an inverse correlation of mortality with the level of AGEs in their blood. ${ }^{26}$

Disappointing separate multicenter trials of aminoguanidine (Pimagidine) were conducted in adults with type 1 and type 2 diabetes and documented, fixed proteinuria of at least 500 $\mathrm{mg} /$ day, and a plasma creatinine concentration of $<1.0 \mathrm{mg} / \mathrm{dL}(88 \mu \mathrm{mol} / \mathrm{L})$ in women or $<1.3$ $\mathrm{mg} / \mathrm{dL}$ (115 $\mu \mathrm{mol} / \mathrm{L})$ randomly assigned to treatment with aminoguanidine or placebo for four years. In the type 1 trial, 56 sites enrolled 69 subjects randomized to receive 150 or $300 \mathrm{mg}$ of 
aminoguanidine orally b.i.d. versus placebo with a mean treatment exposure of 2.5 years. Throughout the study, more than $90 \%$ of subjects in both treatment and placebo groups were concurrently treated with either an angiotensinconverting enzyme inhibitor or receptor blocker. Compared with the placebo group, the aminoguanidine group evinced a significant $(<0.05)$ reduction in doubling of serum creatinine concentration in those who had proteinuria $>2 \mathrm{~g} / 24 \mathrm{~h}$. There was a non-significant "trend" toward slowing the creatinine rise in the entire group. Simultaneously, protection against diabetic retinopathy and a decrease in hyperlipidemia was noted in the treated group. Side effects in the aminoguanidine group included a transient flu-like syndrome, worsening anemia, and development of antinuclear autoantibodies (ANA). ${ }^{27}$ A similar study in 599 subjects with type 2 diabetes enrolled in 84 centers in Canada and the US was interrupted because of liver function abnormalities in the aminoguanidine treated group. Other adverse effects of aminoguanidine treatment included myocardial infarction, congestive heart failure, atrial fibrillation, anemia, ANA titer conversion, and upper gastrointestinal symptoms. ${ }^{28}$

AGE induced nephrotoxicity in diabetes has been linked to activation of protein kinase C (PKC) isoforms that promote oxidative stress. Ruboxistaurin mesylate, a bisindolylmaleimide with high specificity within the PKC gene family, inhibits PKC beta isoforms. In the streptozotocin (STZ) rat, Lepr(db)/Lepr(db) mouse, and STZRen 2 rat models of diabetes, ruboxistaurin normalized glomerular hyperfiltration, decreased urinary albumin excretion, and reduced glomerular transforming growth factor-beta1 and extracellular matrix protein production. ${ }^{29}$ Tuttle et al. completed a promising 1 year randomized, double-blind, placebo-controlled, multicenter, pilot study in which $32 \mathrm{mg} /$ day of ruboxistaurin was administered for 1 year to 123 persons with type 2 diabetes and persistent albuminuria (albumin-to-creatinine ratio (ACR) 200-2,000 $\mathrm{mg} / \mathrm{g}$ ), despite therapy with reninangiotensin system inhibitors. Employing endpoints of change in ACR and estimated glomerular filtration rate (eGFR) after 1 year, urinary ACR decreased significantly $(-24 \pm 9 \%)$ in participants treated with ruboxistaurin $(P=0.020)$ and non-significantly $(-9 \pm 11 \%)$ in the placebo group $(P=0.430)$. Encouragingly, eGFR did not decline significantly in the ruboxistaurin group ($2.5 \pm 1.9 \mathrm{~mL} / \mathrm{min}$ per $\left.1.73 \mathrm{~m}^{2}\right)(P=0.185)$, but the placebo group lost significant eGFR over 1 year (-
$4.8 \pm 1.8 \mathrm{~mL} / \mathrm{min}$ per $\left.1.73 \mathrm{~m}^{2}\right)(P=0.009) .{ }^{30}$

Clinical application of aminoguanidine (2775 Library of Medicine citations as of June 2009), related molecules, or AGE breakers remains a promise unfulfilled. Lessons learned from broad investigative experience with aminoguanidine center about the species differences between induced diabetes in the rat, diabetes in the dog, and the human disease. No further human trials of aminoguanidine are planned. That AGEs and RAGE persist as a target for both prevention and amelioration of diabetic micro- and macrovascular complications is evident from current evaluations of other drugs such as TRC4186, an AGE breaker. ${ }^{31}$ When injected intraperitoneally at a dose of 9 or $27 \mathrm{mg} / \mathrm{kg}$ twice daily in obese Zucker spontaneously hypertensive diabetic rats, TRC4186, $27 \mathrm{mg} / \mathrm{kg}$, prevented onset of hypertension while protecting against loss of renal function as evident from a preserved albumin to creatinine ratio and normal renal histopathology. Also disappointing, after a positive placebo controlled evaluation in a six month trial in diabetic peripheral neuropathy,32 ruboxistaurin had a negative placebo controlled prospective trial of its value in improving sensory nerve function in cutaneous diabetic neuropathy. 33

\section{IS THE PANDEMIC OF ESRD IN THOSE WITH DIABETES SUBSIDING?}

First inferred from a study of ESRD incidence plotted by rate between 2000 and 2003 is the actual decline, interpreted as a major change in the epidemic "growth curve" (Figure 3), of renal failure in those with diabetes. Commenting on this "good news" presented at the end of 2005 in the Centers for Disease Control and Prevention (CDC)'s Weekly Morbidity and Mortality Report noted: "Although the number of new cases of ESRD in persons with diabetes increased overall, the incidence of ESRD-DM among persons with diabetes is not increasing among black, Hispanics, men, and persons aged 65-74 years, and is declining among persons aged $<65$ years, women, and whites (figures 4, 5)". 34 Employing as denominator all persons known to have diabetes with new incidence of ESRD as numerator revealed a remarkable sharply downward slope from a peak of 305 per 100,000 in 1996 to 232 in $2002(P<0.01)$.

Thus, as the total United States population continues to increase, the number of diabetic persons will also increase but the proportion (rate) of diabetic individuals who will develop ESRD is falling and, by trend analysis, should 
continue to decrease. Why this encouraging transformation is taking place is a provocative cause for speculation. Assigning credit to the presently widely applied regimen encompassed by renoprotection is attractive. 35 For persons with diabetes, key components of renoprotection include:

\section{MANAGING THE DIABETIC PATIENT}

Once it is evident that the cause of renal perturbed function in a specific patient is diabetes, a strategy to prevent or delay major diabetic complications is implemented. Initially, this means establishing a program to optimize glucose control, normalize blood pressure and plasma lipids while effecting a healthy life style that includes regular exercise and a non-atherogenic diet. A key concern in constructing a treatment plan to minimize the complexity of complications in diabetes is the confusing number of drugs prescribed often at a co-payment cost that strains the patient's budget. The subject of medication expense should be addressed repeatedly to seek lest costly substitutes.

\section{BLOCKING ANGIOTENSIN-CONVERTING ENZYME ${ }^{36}$}

The adverse effect of hypertension on the course of intrinsic renal disease of any etiology is broadly appreciated. Normalizing a hypertensive blood pressure is a bedrock component of all regimens for contemporary renal care. In persons with diabetes, improvement in both the quantity of protein "leaked" into urine and the extent of normalization of hypertensive blood pressure are enhanced by treatment with an angiotensinconverting enzyme inhibitor and/or an angiotensin receptor blocker. Multiple studies and the American Diabetes Association Clinical Practice Recommendations for 2008 sustain inclusion of these drugs as first line medications in a renoprotective regimen. ${ }^{37}$ The natural history of diabetic nephropathy, in terms of duration of stages of chronic kidney disease (CKD) prior to onset of ESRD, $3^{8}$ has required continuous revision to reflect an improving prognosis, meaning extension of each phase of chronic kidney disease, 39 in patients under treatment with an angiotensinconverting enzyme inhibitor (ACEi) and/or an angiotensin receptor blocker (ARB). A current advisory as to evidence based regimens holds that the renin-angiotensin-aldosterone system (RAAS) when effectively blocked by ACEi or ARB offers benefit beyond that attributable to blood pressure lowering alone by decreasing proteinu- ria, a risk marker for renal disease progression. $4^{4}$ Their antiproteinuric effect correlates with their kidney protection. Mounting evidence defends the hypothesis that higher doses of ACEi plus an ARB as dual RAAS blockade are more effective in reducing proteinuria increasing renoprotection..$^{11}$

\section{STRIVING FOR EUGLYCEMIA4²}

Guidelines developed by the American Diabetes Association for metabolic regulation of individuals with diabetes, 43 striving for a glycosylated hemoglobin level (HbA1c) of $<7 \%$, are not only attainable but actually cost effective for the health care system. 44 That intensive metabolic control pays off in terms of slowing micro- and macrovasculopathy is a central tenet of current treatment strategies derived from unequivocal findings in the American Diabetes Control and Complication Trial (DCCT) 45 and the British United Kingdom Prospective Diabetes Trial. (UKPDS). ${ }^{6}$ Recently, however, two large trials (ACCORD (Action to Control Cardiovascular Risk in Diabetes)47 and ADVANCE (Action in Diabetes and Vascular Disase: Preterax and Diamicron Modified Release Controlled Evaluation trial) ${ }^{48}$ ) in type 2 diabetes compared the effect on cardiovascular complications of intensive and standard regimens of glucose regulation, and both indicated that near-normal glycemic control for a median of 3.5 to 5 years did not reduce cardiovascular events within that time frame. Most disturbing was the finding in the ACCORD trial that the risk of death was increased by "effective metabolic control". The recently reported NiceSugar study casts further doubt on striving for strict glucose control in an intensive care setting finding that mortality at 90 days was $27.9 \%$ for strict glucose control versus $24.9 \%$ for conventional glucose control, $P=0.02$, concluding: "No additional benefit from lowering of blood glucose levels below approximately 140 to $180 \mathrm{mg} / \mathrm{dL}$; indeed, for unclear reasons, there may be some risk".49 A formal statement from in the British Medical Association advises: "The change of target A1c from $7.5 \%$ to $7 \%$ should be withdrawn before it wastes resources and possibly harms patients".50

For the present, clinicians should regard the target for overall metabolic regulation in both types 1 and 2 diabetes to be a glycated hemoglobin of $7 \%$ with the understanding that while tighter control may benefit retarding of microvascular complications, the genesis of the excess deaths that prompted early termination of the ACCORD trial require further study before advo- 
cating a lower target. All other aspects of renoprotection continue as the mainstay of present diabetes care.

\section{CORRECTING DYSLIPIDEMIA51,52}

Studies reported over the past five years link progressive nephropathy in persons with diabetes to elevated LDL cholesterol and hypertriglyceridemia as risk factors separate from proteinuria (microalbuminuria53). The American Diabetes Association advocates that adult patients be tested "at least annually and more often to achieve goals" of an $\mathrm{LDL}<100 \mathrm{mg} / \mathrm{dL}$ with triglycerides $<150$ $\mathrm{mg} / \mathrm{dL}$ using statins and other lipid-lowering agents as necessary. 54

Stopping cigarette smoking, 55 reducing excess weight, 56 incorporating exercise in an overall program of Life Style Modification. ${ }^{77,58}$

Whether successful alteration in life style should receive any credit for improvement in the course of those with diabetes is difficult to substantiate. Smoking cessation, weight reduction, and incorporation of foods viewed as "healthy", are objectives more extolled than attained. Other than limited reports of low level reductions in smoking or sustained weight loss at one year, the advice though well motivated is largely hopeful rather than predictive of change. Indeed, a recent report of the proportion of persons with diabetes who actually followed advised Life Style Criteria found that only $15 \%$ of 40,000 healthy subjects participating in the National Health and Nutrition Examination Survey (NHANES 3) were adherent in 1988, of whom 8\% continued their modified behavior 18 years later in 2006.59

Epidemiology as applied to human events is more a descriptive than a hard science. Witness our present apprehension and absence of hard information as the world prepares for what many view will be a devastating pandemic of $\mathrm{H}_{5} \mathrm{~N} 1$ avian influenza. ${ }^{60,61}$ It follows that what appears to be a favorable, albeit of major medical, economic, and social impact, change in course in the epidemic curve for ESRD in diabetes must be viewed with cautious optimism rather than acceptance as fact. Nevertheless, it is inviting to ascribe benefit to a renoprotective regimen that demands so much from patients in its grasp. As documented by the USRDS, there has been a substantive increase in the proportion of "nonESRD” diabetic individuals receiving a therapeutic regimen containing ACEi/ARB angiotensin blockade and/or lipid lowering drugs therefore meeting the definition of renoprotection. ${ }^{62}$ Credit for the declining incidence rate of ESRD in di- abetic persons may also be due, in part, to success in the difficult to attain life style modifications of weight loss, exercise, and smoking cessation advocated by the American Diabetes Association. ${ }^{63}$ As noted in the Washington Post on March 9, 2006: "Americans smoked fewer cigarettes last year than at any time since 1951 ... a 4.2 percent decline in 2005 alone". ${ }^{64}$ Growing evidence suggests that combining an ACEi with an ARB retards progression of chronic kidney disease by optimizing reduction of proteinuria irrespective of the etiology or character of the renal disorder. 65

\section{MANAGING ESRD}

Choices for long-term management of irreversible uremia in diabetic patients contain the same modalities as for treating renal failure in nondiabetic patients with two additional concerns:

1. Diabetic patients generally have severe comorbidities indicating macro- and microvascular injury.

2. Pancreas and islet transplants have been successfully performed in type 1 diabetes and experimentally in selected patients with type 2 diabetes. Table 1 lists therapeutic options for diabetic ESRD patients.

Table 1. Options in uremia therapy for diabetic ESRD patients.

1. No specific uremia intervention $=$ passive suicide

2. Peritoneal dialysis Intermittent peritoneal dialysis (IPD)

Continuous ambulatory peritoneal dialysis (CAPD)

Continuous cyclic peritoneal dialysis (CCPD)

3. Hemodialysis

Facility hemodialysis

Home hemodialysis

Daily hemodialysis (nocturnal)

4. Renal transplantation

Deceased donor kidney

Living donor kidney

5. Pancreas plus kidney transplantation

Type 1

?Type 2 (application increasing)

Comparison between peritoneal dialysis, he- 
Table 2. Composition of end stage renal disease options for diabetic patients

\begin{tabular}{|c|c|c|c|}
\hline Factor & Peritoneal Dialysis & Hemodialysis & Kidney Transplant \\
\hline Extrarenal disease & No limitation & No if hypotensive & No if severe heart disease \\
\hline Geriatric patients & No limitation & No limitation & Arbitrary by program \\
\hline Full rehabilitation & Rare, if ever & Rare & Common with graft functions \\
\hline Death rate & Higher than non-diabetics & Higher than non-diabetics & $\begin{array}{l}\text { Slightly higher than non- } \\
\text { diabetics }\end{array}$ \\
\hline First year survival & About $75-80 \%$ & About $75-80 \%$ & Above 95\% \\
\hline Survival $>10$ years & Almost never & Fewer than $5 \%$ & About one-half \\
\hline $\begin{array}{l}\text { Complications of } \\
\text { diabetes }\end{array}$ & $\begin{array}{l}\text { Usual plus hyperglycemia } \\
\text { and hyperlipidemia }\end{array}$ & Usual for diabetes & $\begin{array}{l}\text { Reduced by functioning trans- } \\
\text { plant }\end{array}$ \\
\hline Special advantage & $\begin{array}{l}\text { Self-performed. No swings in } \\
\text { blood volume level. }\end{array}$ & $\begin{array}{l}\text { Can be self-performed. } \\
\text { Efficient. }\end{array}$ & $\begin{array}{l}\text { Travel freedom. Eye and nerve } \\
\text { problems may improve }\end{array}$ \\
\hline Disadvantage & $\begin{array}{l}\text { Peritonitis. Long hours of } \\
\text { treatment. More days hospi- } \\
\text { talized. }\end{array}$ & $\begin{array}{l}\text { Clotting or infected access. } \\
\text { Depression, weakness }\end{array}$ & $\begin{array}{l}\text { Cosmetic disfigurement, } \\
\text { Cost of cytotoxic drugs. } \\
\text { Induced malignancy. } \\
\text { HIV transmission. }\end{array}$ \\
\hline Patient acceptance & $\begin{array}{l}\text { Variable, usual passive toler- } \\
\text { ance for regimen. }\end{array}$ & $\begin{array}{l}\text { Variable, usual passive tolerance } \\
\text { for regimen. }\end{array}$ & $\begin{array}{l}\text { Enthusiastic so long as graft } \\
\text { functions. Exalted when pan- } \\
\text { creas normalizes glucose }\end{array}$ \\
\hline Biased comparisons & $\begin{array}{l}\text { First choice by enthusiasts, } \\
\text { long-term fatigue and switch } \\
\text { to hemodialysis. }\end{array}$ & $\begin{array}{l}\text { Default for }>80 \% \text {. Complicated by } \\
\text { heart and vascular disease. }\end{array}$ & $\begin{array}{l}\text { Selection of healthiest and } \\
\text { youngest patients favorably } \\
\text { predjudices outcome. }\end{array}$ \\
\hline Relative cost & $\begin{array}{l}\text { First year less than kidney } \\
\text { transplant, subsequent years } \\
\text { more expensive. }\end{array}$ & $\begin{array}{l}\text { First year less than transplant, } \\
\text { subsequent years more expensive. }\end{array}$ & $\begin{array}{l}\text { After first year, kidney trans- } \\
\text { plant - alone - lowest cost } \\
\text { option. }\end{array}$ \\
\hline
\end{tabular}

modialysis and kidney transplantation are listed in Table 2.

\section{PROMISE OF PROTEOMICS}

Following the previously unimaginable impact of DNA testing into the professions of criminology and security, the rapidly evolving ability to exploit minute amounts of protein in serum and urine is transforming the practice of medicine. Although discovery and quantification of microalbuminuria is the only non-invasive current marker for diagnosing diabetic nephropathy contingent on the presence of immunoreactive forms of albumin, it may soon be possible to detect immunounreactive forms as well as other proteins that serve as biomarkers for various stages of renal injury in diabetes. ${ }^{66}$ Both early detection and assessment of prognosis in diabetic nephropathy appeared probable from an evaluation of urinary biomarkers in 305 individuals with diabetic and non-diabetic proteinuric renal disease employing high-resolution capillary electrophoresis coupled with electronspray ionization mass spectrometry. ${ }^{67}$ Among subjects with diabetes, 102 biomarkers differed significantly between those with and without nephropathy permitting $97 \%$ sensitivity and specificity in identifying the CKD as due to diabetes. An example of what to expect is afforded by a proteomic analysis of individuals at risk to type 2 di- 
abetes discerning varying risk according to single-nucleotide polymorphisms (SNPs) in the peroxisome proliferator-activated receptor-delta gene (PPARD), i.e. rs1053049, rs6902123, and rs2267668, allowing prediction of improvement of mitochondrial function, aerobic physical fitness, and insulin sensitivity by life style intervention, as well as consequent distribution of adiposity, hepatic fat storage, and relative muscle mass. 68

A glimpse of answers attainable via proteomic urine study was afforded by study of stored urine samples from Pima Indians with type 2 diabetes 10 years after their entry into a registry when they had no evidence of diabetic nephropathy (serum creatinine levels $<1.2 \mathrm{mg} / \mathrm{dL}$ and urine albumin excretion $<30 \mathrm{mg} / \mathrm{g}$ ). ${ }^{69}$ Using surfaceenhanced laser desorption/ionization time-offlight mass spectrometry to compare 14 individuals who progressed to nephropathy with 14 who did not, 714 unique urine protein peaks were detected and organized into a 12-peak "signature" permitting correct prediction of nephropathy (89\%) with 93\% sensitivity.

Recently, to study the genesis of proteinuria in individuals with type 1 diabetes, the urine proteome in 12 healthy non-diabetic individuals was compared with the urine proteome in 12 subjects with type 1 diabetes and normal urinary albumin excretion rates as well as 12 subjects with type 1 diabetes and microalbuminuria. ${ }^{70}$ Megalin and cubilin, two multiligand receptors expressed in kidney proximal tubule cells that enable reuptake of filtered albumin and megalin/cubilin ligands, were significantly increased in those with type 1 diabetes and microalbuminuria compared with the other two groups. Whether this finding is causative of or a response to microalbuminuria has yet to be determined. Similarly, pursuing the pathobiology of early renal changes in diabetes was explored by identifying urinary proteomes using a fluorescence-based difference gel electrophoresis and mass spectrometry techniques to identify novel biomarkers in urine samples from individuals with type 2 diabetes and normoalbuminuria, microalbuminuria, macroalbuminuria, and a control group without diabetes. E-cadherin, a specific biomarker was also studied by Western blot in urine samples and immunohistochemistry in renal biopsies. Compared with non-diabetic control subjects, urinary E-cadherin, was up-regulated 1.3-fold, 5.2-fold and 8.5-fold in those with diabetes and normoalbuminuria, microalbuminuria and macroalbuminuria respectively. The sensitivity and specificity of urinary E-cadherin for diagnosis of diabetes were $78.8 \%$ (95\% CI, 74-83\%) supporting the quest for urine biomarkers of clinical diagnostic value to detect the onset of diabetic nephropathy. And this is just the beginning application of what may, in the future, be termed urinomics.

\section{NEXT STEPS}

Until the vision of curing diabetes by molecular intervention, stem cell ${ }^{11}$ or islet cell infusion ${ }^{72}$ or xenogeneic pancreas-kidney solid organ transplantation is fulfilled, arduous renoprotective regimens, described above, persists as an effective means for patients with diabetes today to raise the probability of maximizing their number of tomorrows.

\section{REFERENCES}

1. U.S. Renal Data System, USRDS 2008 Annual Data Report: Atlas of End-Stage Renal Disease in the United States, National Institutes of Health, National Institute of Diabetes and Digestive and Kidney Diseases, Bethesda, MD, 2008.

2. World Health Organization, Fact sheet $\mathrm{N}^{\circ} 312$, November 2008; WHO Media centre.

3. Friedman EA. Coping with the coming pandemic of renal failure due to diabetes mellitus. Facta Universitatis 2003;1:1-15.

4. Mauer SM, Chavers BM. A comparison of kidney disease in type I and type II diabetes. Adv Exp Med Biol 1985;189:299-303.

5. Sheehy MJ. HLA and insulin-dependent diabetes. A protective perspective. Diabetes 1992; 41:123-9. doi:10.2337/diabetes.41.2.123

6. Biesenback G, Janko O, Zazgornik J. Similar rate of progression in the predialysis phase in type I and type II diabetes mellitus. Nephrol Dial Transplant 1994;9:1097-1102.

7. Wirta O, Pasternack A, Laippala P, Turjanmaa V. Glomerular filtration rate and kidney size after six years disease duration in non-insulin-dependent diabetic subjects. Clinical Nephrology 1996;45:107.

8. Abourizk NN, Dunn JC. Types of diabetes according to National Diabetes Data Group Classification. Limited applicability and need to revisit. Diabetes Care 1990;13:1120-2.

9. Brownlee M, Cerami A, Vlassara H. Advanced glycosylation end products in tissue and the biochem- 
ical basis of diabetic complications. N Engl J Med 1988;318:1315-21.

10. Brownlee M, Hirsch IB. Glycemic variability: a hemoglobin A1c-independent risk factor for diabetic complications. JAMA 2006;295:1707-8. doi:10.1001/ jama.295.14.1707

11. Koka V, Wang W, Huang XR, Kim-Mitsuyama S, Truong LD, Lan HY. Advanced glycation end products activate a chymase-dependent angiotensin II-gene-rating pathway in diabetic complications. Circulation. 2006;113:1353-60. doi:10.1161/ CIRCULATIONAHA. 105.575589

12. Ceriello A. Oxidative stress and diabetesassociated complications. Endocr Pract 2006;12 Suppl 1:60-2.

13. Kim JA, Wei Y, Sowers JR. Role of mitochondrial dysfunction in insulin resistance. Circ Res 2008; 102:401-14.doi:10.1161/CIRCRESAHA.107.1654 72

14. Sabbatini M, Sansone G, Uccello F, Giliberti A, Conte G, Andreucci VE. Early glycosylation products induce glomerular hyperfiltration in normal rats. Kidney Int 1992;42:875-81. doi:10.1038/ki. 1992.363

15. Moncada S, Palmer RM, Higgs EA. Nitric oxide: physiology, pathophysiology, and pharmacology. Pharmacological Reviews 1991;43:109-42

16. Bank N, Aynedjian HS. Role of EDRF (nitric oxide) in diabetic renal hyperfiltration. Kidney Int 1993;43:1306-12. doi:10.1038/ki.1993.183.

17. Bucala R, Tracey KJ, Cerami A. Advanced glycosylation products quench nitric oxide and mediate defective endothelium-dependent vasodilation in experimental diabetes. J Clin Invest 1991;87:43238. doi:10.1172/JCI115014

18. Edelstein D, Brownlee M. Mechanistic studies of advanced glycosylation end product inhibition by aminoguanidine. Diabetes 1992;41:26-9. doi:10. 2337/diabetes.41.1.26

19. Brownlee M, Vlassara H, Kooney T, Ulrich P, Cerami A. Aminoguanidine prevents diabetesinduced arterial wall protein cross-linking. Science 1986;232:1629-32. doi:10.1126/science.3487117

20. Swamy-Mruthinti S, Green K, Abraham EC. Inhibition of cataracts in moderately diabetic rats by aminoguanidine. Experimental Eye Research 1996;62:505-10. doi:10.1006/exer. 1996.0061

21. Soulis-Liparota T, Cooper ME, Dunlop M, Jerums $\mathrm{G}$. The relative roles of advanced glycation, oxidation and aldose reductase inhibition in the development of experimental diabetic nephropathy in the Sprague-Dawley rat. Diabetologia 1995;38:
387-94. doi:10.1007/ BFo0410275

22. Ellis EN, Good BH. Prevention of glomerular basement membrane thickening by aminoguanidine in experimental diabetes mellitus. Metabolism 1991;40: 1016-9. doi:10.1016/0026-0495(91) 90122-D

23. Vlassara H. Serum advanced glycosylation end products: a new class of uremic toxins? Blood Purif 1994;12:54-9. doi:10.1159/000170145

24. Papanastasiou P, Grass L, Rodela H, Patrikarea A, Oreopoulos D, Diamandis EP. Immunological quantification of advanced glycosylation endproducts in the serum of patients on hemodialysis or CAPD. Kidney Internat 1994;46:216-22. doi:10. $\underline{1038 / \mathrm{ki} .1994 .262}$

25. Makita Z, Radoff S, Rayfield EJ, et al. Advanced glycosylation end products in patients with diabetic nephropathy. New Engl J Med 1991;325:836-42.

26. Schwedler SB, Metzger T, Schinzel R, Wanner C. Advanced glycation end products and mortality in hemodialysis patients. Kidney Int. 2002;62:30110. doi:10.1046/j.1523-1755.2002.00423.x

27. Whittier F, Spinowitz B, Wuerth JP, Cartwright K. Pimagidine (PG) safety profile in patients with Type I diabetes mellitus (DM). J Am Soc Nephrol 1999; 10:184A (abstract).

28. Freedman BI, Wuerth JP, Cartwright K, et al. Design and baseline characteristics for the aminoguanidine Clinical Trial in Overt Type 2 Diabetic Nephropathy (ACTION II). Control Clin Trials 1999;20:453-510. doi:10.1016/S0197-2456(99)oo 024-O

29. The PKC-DRS Study Group. The effect of ruboxistaurin on visual loss in patients with moderately severe to very severe nonproliferative diabetic retinopathy: initial results of the Protein Kinase C beta Inhibitor Diabetic Retinopathy Study (PKCDRS) multicenter randomized clinical trial. Diabetes 2005;54:2188-97. doi:10.2337/diabetes.54. 7.2188

30. Tuttle KR, Bakris GL, Toto RD, McGill JB, Hu K. The effect of ruboxistaurin on nephropathy in type 2 diabetes. Diabetes Care 2005;28:2686-90. doi:10.2337 / diacare.28.11.2686

31. Joshi D, Gupta R, Dubey A, et al. TRC4186, a novel AGE-breaker, improves diabetic cardiomyopathy and nephropathy in Ob-ZSF1 model of type 2 diabetes. J Cardiovasc Pharmaco 2009;54:72-81. doi:10.1097/ FJC.obo13e3181ac3a34

32. Casellini CM, Barlow PM, Rice AL, et al. A 6month, randomized, double-masked, placebo- 
controlled study evaluating the effects of the protein kinase C-beta inhibitor ruboxistaurin on skin microvascular blood flow and other measures of diabetic peripheral neuropathy. Diabetes Care 2007;30:896-902. doi:10.2337/dco6-1699

33. Brooks B, Delaney-Robinson C, Molyneaux L, Yue DK. Endothelial and neural regulation of skin microvascular blood flow in patients with diabetic peripheral neuropathy: effect of treatment with the isoform-specific protein kinase $\mathrm{C}$ beta inhibitor, ruboxistaurin. J Diabetes Complications 2008;22: 88-95. doi:10.1016/j.jdiacomp.2007.07.002

34. CDC. Incidence of end-stage renal disease among persons with diabetes - United States, 19902002. MMWR 2005;54:1097-1100.

35. Miyata T, van Ypersele de Strihou C. Renoprotection of angiotensin receptor blockers: beyond blood pressure lowering. Nephrol Dial Transplant 2006;21: 846-9. doi:10.1093/ndt/gflo13

36. So WY, Ma RCW, Ozaki R, et al. Angiotensinconverting enzyme (ACE) inhibition in type 2, diabetic patients - interaction with ACE insertion/deletion polymorphism. Kidney Int 2006;69: 1438-43.

37. American Diabetes Association. Standards of medical care in diabetes - 2009. Diabetes Care 2009;32 Suppl 1:S13-S61. doi:10.2337/dco9-S013

38. Levey AS, Eckardt KU, Tsukamoto Y, et al. Definition and classification of chronic kidney disease: a position statement from Kidney Disease: Improving Global Outcomes (KDIGO). Kidney Int 2005;67:2089-100. doi:10.1111/j.1523-1755.2005. $\underline{00365 . x}$

39. Kong AP, So WY, Szeto CC, et al. Assessment of glomerular filtration rate in addition to albuminuria is important in managing type II diabetes. Kidney Int 2006;69:383-7. doi:10.1038/sj.ki.5000061

40. Bakris GL. Slowing nephropathy progression: focus on proteinuria reduction. Clin J Am Soc Nephrol 2008;3 Suppl 1:S3-S10. doi:10.2215/CJN. $\underline{03250807}$

41. Bakris GL, Weir MR. Comparison of dual RAAS blockade and higher-dose RAAS inhibition on nephropathy progression. Postgrad Med 2008;120:33-42. doi:10.3810/pgm.2008.04.1758

42. Bode BW, Schwartz S, Stubbs HA, Block JE. Glycemic characteristics in continuously monitored patients with type 1 and type 2 diabetes: normative values. Diabetes Care 2005;28:2361-6. doi:10. 2337/diacare.28.10.2361

43. American Diabetes Association, Standards of Med- ical Care in Diabetes -2008. Diabetes Care 2008; 31, Suppl 1, S5-S11. doi:10.2337/dco8-So05

44. Dijkstra RF, Niessen LW, Braspenning JC, Adang E, Grol RT. Patient-centred and professionaldirected implementation strategies for diabetes guidelines: a cluster-randomized trial-based costeffectiveness analysis. Diabet Med 2006;23:16470. doi:10.1111/j.1464-5491.2005.01751.x

45. McCarter RJ, Hempe JM, Chalew SA. Mean blood glucose and biological variation have greater influence on HbA1c levels than glucose instability: an analysis of data from the Diabetes Control and Complications Trial. Diabetes Care 2006;29:352-5. doi:10. 2337/diacare.29.02.06.dc05-1594

46. Clarke PM, Gray AM, Briggs A, Stevens RJ, Matthews DR, Holman RR; UKPDS 72 United Kingdom Prospective Diabetes Study. Cost-utility analyses of intensive blood glucose and tight blood pressure control in type 2 diabetes (UKPDS 72). Diabetologia 2005;48:868-77. doi:10.1007/s00125 -005-1717-3

47. The Action to Control Cardiovascular Risk in Diabetes Study Group. Effects of intensive glucose lowering in type 2 diabetes. $\mathrm{N}$ Engl $\mathrm{J}$ Med 2008:358:2545-59. doi:10.1056/NEJMoa0802743

48. ADVANCE Collaborative Group, Patel A, MacMahon $\mathrm{S}$, Chalmers $\mathrm{J}$, et al. Intensive blood glucose control and vascular outcomes in patients with type 2 diabetes. N Engl J Med 2008;358:2560-72. doi:10. 1056/NEJMoa0802987

49. NICE-SUGAR Study Investigators, Finfer S, Chittock DR, Su SY, et al. Intensive versus conventional glucose control in critically ill patients. N Engl J Med 2009;360:1283-97. doi:10.1056/NEJMoao8 10625

50. Harnden A, Lehman R. New primary care series: Easily missed? BMJ. 2009;338:901-2. doi:10. 1136 /bmj.b491

51. Benner D. K/DOQI gets to the heart of managing dyslipidemias in patients with CKD. Nephrol Nurs J 2005;32:337-8.

52. Ridderstråle M, Gudbjörnsdottir S, Eliasson B, Nilsson PM, Cederholm J; Steering Committee of the Swedish National Diabetes Register (NDR). Obesity and cardiovascular risk factors in type 2 diabetes: results from the Swedish National Diabetes Register. J Intern Med 2006;259:314-22. doi:10.1111/j.1365-2796.2006.01617.x

53. Thomas MC, Rosengård-Bärlund M, Mills V, et al. Serum lipids and the progression of nephropathy in type 1 diabetes. Diabetes Care 2006;29:317-22. 


\section{doi:10 .2337/diacare.29.02.06.dco5-0809}

54. American Diabetes Associatioin.Standards of Medical Care in Diabetes - 2006. Diabetes Care 2006; 29, Suppl 1, S4-S42.

55. Nilsson PM, Gudbjörnsdottir S, Eliasson B, Cederholm J; Steering Committee of the Swedish National Diabetes Register. Smoking is associated with increased HbA1c values and microalbuminuria in patients with diabetes - data from the National Diabetes Register in Sweden. Diabetes Metab 2004;30:261-8. doi:10.1016/S1262-3636(07) 70117-9

56. De Nicola L, Minutolo R, Chiodini P, et al. Global approach to cardiovascular risk in chronic kidney disease: Reality and opportunities for intervention. Kidney Int 2006;69:538-45. doi:10.1038/sj.ki. 5000085

57. Evans N, Forsyth E. End-stage renal disease in people with type 2 diabetes: systemic manifestations and exercise implications. Phys Ther 2004; 84:454-63.

58. Ritz E, Schwenger V Lifestyle modification and progressive renal failure. Nephrology (Carlton). 2005;10:387-92. doi:10.1111/j.1440-1797.2005. 00439.X

59. King DE, Mainous AG 3rd, Carnemolla M, Everett CJ. Adherence to healthy lifestyle habits in US adults, 1988-2006. Am J Med 2009;122:528-34. doi:10.1016/j.amjmed.2008.11.013

6o. Enserink M. Influenza: new study casts doubt on plans for pandemic containment. Science 2006; 311:1084. doi:10.1126/science.311.5764.1084a

61. Dowdle WR. Influenza pandemic periodicity, virus recycling, and the art of risk assessment. Emerg Infect Dis 2006;12:34-39.

62. U.S. Renal Data System, USRDS 2005 Annual Data Report: atlas of end-stage renal disease in the united states, national institutes of health, national institute of diabetes and digestive and kidney diseases, Bethesda, MD, 2005. Cumulative percent of diabetic patients with CVD receiving ACEIs/ARBs, by age \& ESRD status, figure 5.26 p 114, Cumulative percent of diabetic patients with CVDreceiving lipid-lowering treatment, by age \& ESRD status, figure 5.29, p 115.

63. American Diabetes Association. Standards of Med- ical Care in Diabetes - 2008. Diabetes Care 2008, Suppl 1;S12-S18. doi:10.2337/dco8-So12

64. Kaufman M. Smoking in U.S. declines sharply. Cigarette sales at a 54-year low. Wasington Post, March 9, 2006, page A01.

65. Bakris GL. Slowing nephropathy progression: focus on proteinuria reduction. Clin $J$ Amer Soc Nephrol 2008;3 Suppl 1:S3-S10. doi:10.2215/CJN. $\underline{03250807}$

66. Thongboonkerd V. Searching for novel biomarkers and new therapeutic targets of diabetic nephropathy using proteomics approaches. Contrib Nephrol 2008;160:37-52. doi:10.1159/000125928

67. Rossing K, Mischak H, Dakna M, et al. Urinary proteomics in diabetes and CKD. J Am Soc Nephrol 2008;19:1283-90. doi:10.1681/ASN.2007091 025

68. Thamer C, Machann J, Stefan N, et al. Variations in PPARD determine the change in body composition during lifestyle intervention: a whole-body magnetic resonance study. J Clin Endocrinol Metab 2008;93:1497-500. doi:10.1210/jc.2007-1209

69. Otu HH, Can H, Spentzos D, et al. Prediction of diabetic nephropathy using urine proteomic profiling 10 years prior to development of nephropathy. Diabetes Care 2007;30:638-43. doi:10.2337/dco6$\underline{16.56}$

70. Thrailkill KM, Nimmo T, Bunn RC, et al. Microalbuminuria in type 1 diabetes mellitus is associated with enhanced excretion of the endocytic, multiligand receptors megalin and cubilin. Diabetes Care 2009;32:1266-8. doi:10.2337/dco9-0112

71. Couri CE, Oliveira MC, Stracieri AB, et al. Cpeptide levels and insulin independence following autologous nonmyeloablative hematopoietic stem cell transplantation in newly diagnosed type 1 diabetes mellitus. JAMA 2009;301:1573-9. doi:10. 1001/jama. 2009.470

72. Wang T, Adcock J, Kuhtreiber W, et al. Successful allotransplantation of encapsulated islets in pancreatectomized canines for diabetic management without the use of immunosuppression. Transplantation 2008;85:331-7. doi:10.1097/TP.obo 13e3181629c25 